\title{
EL PARO CÍVICO NACIONAL DEL 14 DE SEPTIEMBRE DE 1977. UN EJERCICIO DE MEMORIA COLECTIVA
}

Mauricio Archila Neira*

L a opinión pública nacional parece haber olvidado que hace varias décadas, un miércoles 14 de septiembre, el país prácticamente se paralizó. Los sentimientos ante la muerte de quien era presidente en ese entonces, Alfonso López Michelsen, y su apoyo al Acuerdo Humanitario, han ocultado su obra de gobierno y las protestas de la gente. Pero en su momento el significado del Paro Cívico Nacional de 1977 fue materia de acalorados debates académicos y sobre todo políticos. En efecto, sobre él se dieron las opiniones más disímiles, desde que fue una insurrección popular -como simultáneamente lo vieron sectores de la derecha y la insurgencia- hasta que representó una mera escaramuza de la oposición ospino-pastranista y de sectores del clero -según las cínicas palabras del mismo López tiempo después. En realidad no fue ni lo uno ni lo otro, y si bien puede ser considerada como la mayor protesta popular de la segunda mitad del siglo xx, su objetivo no fue derrocar el régimen. Aunque en sentido estricto es un hecho irrepetible, como ocurre con los eventos históricos, su significado y las lecciones que nos dejó deben ser rescatados del olvido colectivo. Realizar dicha tarea es el objetivo de este ensayo, que mirará brevemente el contexto del Paro y luego propondrá algunas claves de lectura sobre su trascendencia y enseñanzas para los colombianos y colombianas del presente.

\footnotetext{
* Profesor titular de la Universidad Nacional e investigador del Cinep, Bogotá, Colombia, [marchilan@unal.edu.co]. Agradezco a Martha Cecilia García por suministrarme las cifras procesadas de las luchas sociales. La versión original se publicó en CEPA 5, 2007, pp. 10-13. Fecha de recepción: 1-08-2016, fecha de aceptación: 20-10-2016. Sugerencia de citación: Archila N., M. "E1 paro cívico nacional del 14 de septiembre de 1977 . Un ejercicio de memoria colectiva", Revista de Economia Institucional 18, 35, 2016, pp. 313-318. Dor: http://dx.doi. org/10.18601/01245996.v18n35.18.
} 
Alfonso López Michelsen subió al poder en 1974 con la mayor votación registrada hasta ese momento $\mathrm{y}$, con el $56 \%$ del total de sufragios, les ganó a sus contendores: el conservador Álvaro Gómez (31\%), María Eugenia Rojas de la Anapo (10\%) y Hernando Echeverri Mejía de la coalición de izquierda uno (2,6\%). No fue poca cosa. Por primera vez desde 1946 había competencia abierta por la presidencia y el régimen del Frente Nacional formalmente desaparecía, aunque la coalición bipartidista subsistiría en forma soterrada otros lustros más. Además, el "pollo" López aprovechó su pasado rebelde para seducir a sectores de la población, cortándole el paso al temido Álvaro y a la oposición anapista y de izquierda. Del reformismo agitado en la campaña, poco se hizo realidad en su "Mandato Claro". Hubo algunos pasos iniciales que despistaron a unos cuantos, como levantar - por poco tiempo- el estado de sitio, otorgar personería jurídica a la central sindical comunista (CSTC) y a la demócrata cristiana (CGT), y reestablecer relaciones con Cuba.

Pero la demagogia lopista pronto se agotó y se hizo evidente su apuesta de favorecer al gran capital gracias a la apertura económica en lo que se designó "el Japón de Suramérica”. López cancelaba así el proteccionismo estatal, del que siempre fue enemigo, mientras se daba libertad de precios y tarifas, pero eso sí controlando los salarios. Intentó hacer una reforma laboral que si bien parecía favorecer el sindicalismo de industria, perjudicaba a los asalariados al desmontar el régimen de prestaciones por medio del salario integral y recortaba el derecho de huelga. En cuanto al campo, la reforma agraria, de la cual tampoco fue simpatizante, se congeló definitivamente y en su lugar aparecieron tímidos programas alimentarios y de "desarrollo rural integrado". En las ciudades tampoco hubo avances sociales sustantivos, y más bien se continuó con el modelo urbano de mayor exclusión y segregación de los sectores populares. La resultante fue que en medio de un crecimiento económico pausado - con un PIB por encima del 3\%- la inflación se desbordó hasta llegar al 35\% en 1977. Obviamente los salarios y en general el poder adquisitivo del pueblo se vieron afectados mientras el gran capital redoblaba sus ganancias.

En lo político mantuvo la paridad bipartidista haciendo difíciles equilibrios entre antiguos rebeldes como María Helena de Crovo y oscuros personajes ligados a la Violencia como Cornelio Reyes. Impuso de nuevo el estado de sitio en 1976 y por el resto de su mandato, mientras les dio carta blanca a los militares en el manejo del orden público. En vano intentó frenar el descontento popular y las limitaciones del aparato judicial con una "Pequeña Constituyente", hundida 
por la Corte Suprema de Justicia. A lo largo de su mandato no cejó en penalizar la protesta tachándola de subversiva e hizo gala de una arrogancia que le costó el desafecto de sectores de la élite, como el ospino-pastranismo, y de las centrales tradicionales UTC у Стс.

En ese caldo de cultivo no es extraño que la protesta popular hubiera aumentado hasta llegar a cifras nunca alcanzadas en la historia contemporánea. Según la Base de Datos de Luchas Sociales del Cinep, en 1975 se registraron 797 protestas -el año pico en ese recuento estadístico-, 540 en 1976 y 359 hasta septiembre de 1977. Pero esta tendencia en el número de luchas puede ser engañosa porque no recoge la cantidad de participantes, que seguramente aumentó en esos años ${ }^{1}$. En todo caso el desafío al gobierno de López ya no provenía de una Anapo moribunda o de una pequeña izquierda electoral, y menos de una insurgencia muy a la defensiva en ese momento. Provenía de la acción social colectiva de distintos sectores populares, que rápidamente desenmascararon el verdadero rostro del "Mandato Claro".

De nuevo apoyados en la Base de Datos del Cinep se destacan tres actores que tenían sobradas razones para protestar: asalariados, estudiantes y pobladores urbanos. Para los primeros, tres cuartas partes de los motivos de sus luchas entre enero de 1975 y septiembre de 1977 fueron reclamos por condiciones de trabajo y especialmente por aumento de salarios. Pero más preocupante fue que el Estado no ejerció a cabalidad sus funciones de regulación de las relaciones laborales. No tenía injerencia en las que se daban en las empresas privadas y, lo que es peor, era el patrono que más violaciones laborales cometía al no cancelar los salarios de sus trabajadores a tiempo y desconocer las normas legales que él mismo había creado. Así, los años del "Mandato Claro" presenciaron un conjunto de huelgas que se destacaron no solo por el número de participantes sino porque paralizaron actividades cruciales de la economía o concitaron solidaridad. Nos referimos a las de los cementeros, los bancarios, los médicos del Seguro Social, los petroleros, los trabajadores del Ingenio Riopaila, de Indupalma y de Vanitex - una huelga predominantemente femenina-, para solo mencionar las más sobresalientes.

El magisterio merece alguna consideración adicional, pues recurrió frecuentemente al paro y fue el sector que más huelguistas aportó. Además de los motivos ya vistos para el conjunto de asalariados en torno al costo de vida, los maestros se vieron afectados por los

1 En el sector sindical sí se puede hacer este cálculo. Las cifras de Álvaro Delgado sobre huelguistas son: 182.763 en 1975, 103.450 al año siguiente, 187.349 para 1997 -sin incluir los participantes en el Paro Cívico que el mismo autor calculó en 1.300.000- y 393.637 en 1978 (Archila y Delgado, 1995, 133). 
incumplimientos del Estado que era su patrón, el mismo que les impuso un Estatuto Docente en 1977. Muy cerca de ellos estuvieron los estudiantes universitarios y de secundaria por parejo. Estos vieron el deterioro de la educación y que las promesas de reformar las universidades públicas -incluso con "experimentos marxistas" como el de Luis Carlos Pérez en la Universidad Nacional- se derrumbaron rápidamente. Realizaron un número de protestas similar al de los asalariados, pero con ritmos diferentes: entre 1975 y 1976 se mantuvo una intensa lucha estudiantil pero decayó vertiginosamente en 1977. Entre los motivos de protesta en los años estudiados sobresale la solidaridad con otros sectores en conflicto $(21,6 \%)$, no solo con los estudiantes cuyos planteles estaban cerrados, sino con asalariados, campesinos, indígenas y pobladores urbanos.

Estos últimos protagonizaron 375 luchas en el periodo señalado, de las cuales el 55,7\% fue por demandas relacionadas con el hábitat: suelos urbanos, vivienda, servicios públicos -especialmente agua en la Costa Atlántica y Barrancabermeja- e infraestructura física. E1 16,8\% de las protestas de pobladores urbanos fue contra el alza del costo de vida y el 5,3\% se relaciona con acciones de solidaridad. A las de este actor se pueden sumar las protestas de los trabajadores independientes que sobreviven en las ciudades, cuyo total en los años reseñados fue de 84, más de la mitad en 1975. En el campo fueron menos numerosas; campesinos e indígenas realizaron 88 protestas en 1975, 39 en el año siguiente y 34 en los nueve primeros meses de 1977.

La revista Alternativa, en un balance de las luchas populares de 1976, percibió las tendencias descritas y concluyó que, a pesar de la aparente multiplicidad de motivos, ellas convergían en el rechazo del costo de vida y del estado de sitio (Alternativa, 1976, 14-15). Estas son precisamente las principales demandas que las centrales sindicales comenzaron a agitar meses antes del Paro Cívico. Como hemos visto, la solidaridad afloraba en muchas de las protestas y por todas partes se sentía la necesidad de que convergieran en una gran jornada unitaria como la que convocaron la CSTC y la CGT, a la que se sumaron las otras centrales, muchas federaciones y organizaciones sociales del campo y la ciudad, así como los grupos de oposición, incluido el ospino-pastransimo, con excepción de algunas sectas maoístas.

No nos detendremos en el relato de los hechos del 14 de septiembre de 1977, sobre los que hay buenas narraciones. Resaltamos solamente algunos de sus rasgos significativos. Fue un paro más cívico o popular que estrictamente laboral, y la ausencia de transportes jugó un papel definitivo. La acción fue muy urbana ya que cubrió las grandes capi- 
tales y muchas intermedias, pero también se extendió a los campos. Aunque fue planeada, hubo desbordes por saqueos a almacenes de la periferia urbana y sobre todo por confrontaciones con las fuerzas militares y de policía, las que a juicio del General Varón Valencia "obraron con mesura y no con debilidad". Sin duda no obraron con debilidad, en cambio, la mesura ni se vio. El saldo de la jornada así lo corrobora: 19 muertos, casi 3.500 detenidos -la gran mayoría en Bogotá- y pérdidas económicas incalculables.

No acababan de terminar los choques y ya se multiplicaban las interpretaciones de la protesta. En la noche del 14, desde la clandestinidad, las centrales dieron parte de victoria, mientras resaltaban el carácter reivindicativo de la protesta. López, en alocución televisada, visiblemente molesto, trató de minimizar la cobertura del paro mientras resaltó el supuesto componente subversivo de la jornada mostrando ante las cámaras las "armas" de la gente: unas cuantas grapas y puntillas. Los militares, el grueso de la clase política tradicional y la gran prensa secundaron dicha interpretación. Por su parte, diversas organizaciones sociales y políticas de izquierda fueron entusiastas en el balance de la jornada, aunque no faltaron voces más moderadas como los indígenas, quienes participaron activamente en el paro convencidos de que no era la solución inmediata de todos los problemas de los explotados pero sí el punto de inicio de una prometedora unión popular (Unidad Indígena, 1977, 6-8). En medio del furor del grueso de la izquierda llama la atención la advertencia de Guillermo Fergusson: "el triunfalismo engendra fantasías voluntaristas llenas de peligros" (Alternativa, 1977, 10).

En la disputa por el significado de la protesta los extremos se tocan. En efecto, un año después, aduciendo un desborde subversivo, se expidió el Estatuto de Seguridad, que legalizó la represión desatada durante el gobierno de Turbay Ayala -otro "prohombre" cuya muerte ocultó su nefasto pasado-. Pocos días más tarde un pequeño grupo armado de "Autodefensa Obrera" -cumpliendo la profecía de Fergusson- asesinó al ex ministro de gobierno Rafael Pardo Buelvas en el baño de su casa. De más trascendencia histórica fue la decisión, tomada por las FARC en su viI Conferencia, de modificar su modo de operar y convertirse en una fuerza ofensiva. El cambio estratégico, a juicio de Medófilo Medina, "se desprendió de un diagnóstico sencillo: el Paro Cívico Nacional [...] había sido una insurrección a la que solo le habían faltado las armas para instaurar el poder popular" $(1997,31)$.

\footnotetext{
${ }^{2}$ Citado en Alape $(1980,156)$.
} 
Pero el balance del Paro del 77 no debe quedarse en criticar esos extremos. La acción sembró la semilla de la unidad sindical, que luego de varios avatares logró concretarse en 1986 con la cut. Los ánimos unitarios también se manifestaron en el campo con los intentos de reconstrucción de la ANUC y la creación de la organización nacional indígena ONIC, y en las ciudades con la convergencia de movimientos cívicos y regionales. Incluso la guerrilla contó con una Coordinadora que permitió la unidad de acción de varios frentes entre los cuales antes había roces. Con todo, el contexto de los años ochenta, en especial por la "guerra sucia", debilitó los propósitos de unidad popular. Hubo intentos de nuevos paros cívicos nacionales, pero fueron duramente reprimidos y carecieron de la amplitud del primero.

Varias décadas después las cosas no han cambiado y en muchos sentidos han empeorado. Tenemos un gobierno autoritario que cuenta con respaldo electoral hasta para ser reelegido. Los ataques a la Constitución de 1991 y la desinstitucionalización son propiciados desde las altas esferas, el conflicto armado se ha degradado desatando una gran crisis humanitaria, los paramilitares están prontos a ingresar a la legalidad y el neoliberalismo campea en la economía. Sin embargo, la gran enseñanza del Paro Cívico Nacional de 1977 es que hay que tener confianza en las posibilidades reales de la unidad popular. Como se ha visto en luchas más recientes - p. ej., en la negativa al referendo constitucional promovido por el entonces presidente Álvaro Uribe en 2003-, cuando los sectores populares se unen, incluidas las organizaciones sociales y políticas de oposición, logran triunfos resonantes. E1 cambio de régimen no es cosa de todos los días, pero nadie excluye que pueda ocurrir cuando hay una amplia movilización popular como la hemos visto en los países vecinos y como se vislumbró aquel día de septiembre de 1977, una fecha que conviene recordar.

\section{REFERENCIAS BIBLIOGRÁFICAS}

1. Alape, A., Un día de septiembre, Bogotá, Ediciones Armadillo, 1980.

2. Alternativa. "Balance de las luchas sociales de 1976", diciembre de 1976, pp. 14-15.

3. Fergusson, G. Columna de opinión, Alternativa 135, octubre de 1977 , p. 10.

4. Archila, M. y Á. Delgado, ¿Dónde está la clase obrera?, Bogotá, Cinep, 1995.

5. Medina, M. "Dos décadas de crisis política en Colombia, 1977-1997", L. G. Arango, comp., La crisis socio-politica colombiana, Bogotá, Universidad Nacional-Fundación Social, 1997.

6. Unidad Indígena. "Participación indígena en el paro cívico, 25 de octubre de 1977, pp. 6-8. 